\title{
PENGEMBANGAN JARINGAN KOMPUTER BERBASIS MIKROTIK PADA SMP NEGERI 8 METRO
}

\author{
Heromadhani ${ }^{1)}$, Sudarmaji ${ }^{2)}$, Arif Hidayat ${ }^{3)}$ \\ ${ }^{\left.1-3^{*}\right)}$ Program Studi IImu Komputer, Fakultas IImu Komputer, \\ Universitas Muhammadiyah Metro \\ Jl. Gatot Subroto, Yosodadi, Metro Timur, Kota Metro
}

\begin{abstract}
Abstrak - Tujuan dari penelitian ini adalah memberikan jaringan komputer dan internet yang ada manajemen bandwidth serta manajemen user yang baik, memperluas ruang lingkup penyebaran jaringan internet pada SMP Negeri 8 Metro. Penelitian ini menggunakan metode Research and Development. Hasil dari penelitian ini berupa pengembangan jaringan komputer dan internet pada SMP Negeri 8 Metro. Diantaranya, dibuatnya konfigurasi manajemen bandwidth serta manajemen user dan memperluas ruang lingkup penyebaran jaringan internet pada SMP Negeri 8 Metro.
\end{abstract}

Kata Kunci : pengembanga, jaringan komputer, manajemen bandwidth, Router Mikrotik

Abstract - The purpose of this study is to provide computer and internet networks that have good bandwidth management and user management, expand the scope of internet network deployment at SMP Negeri 8 Metro. This study uses the Research and Development method. The result of this research is the development of a computer network and internet at SMP Negeri 8 Metro. Among them, the configuration of bandwidth management and user management and expanding the scope of internet network deployment at SMP Negeri 8 Metro was made.

Keywords: computer network development, bandwidth management, Mikrotik Router

\section{PENDAHULUAN}

Internet pada saat ini merupakan satu hal yang sangat dibutuhkan oleh manusia modern, hampir semua aktivitas perlu menggunakan media internet. SMP Negeri 8 Kota Metro Provinsi Lampung adalah salah satu sekolah yang sekarang menerapkan jaringan internet menggunakan Wifi dan LAN sebagai bagian dari aktivitas dan media informasi yang ada di SMP Negeri 8 Kota Metro, terutama di laboratorium komputer, ruang guru dan perpustakaan. Seiring berjalannya waktu timbul masalah baru setelah pandemi covid-19 melanda Indonesia. Akibat tidak diperbolehkannya siswa untuk datang ke sekolah maka guru-guru harus melakukan proses belajar mengajar melalui media internet, yang dimana setiap ruangan membutuhkan akses internet yang optimal dan stabil, tapi jaringan yang ada saat ini memiliki kinerja jaringan yang tidak stabil, hal ini disebabkan adanya penggunaan jaringan internet dengan ukuran yang besar yang dapat mengganggu performa pada jaringan tersebut, dikarenakan sistem jaringan yang ada sekarang belum memiliki management bandwidth dan management user yang baik. Dari permasalahan tersebut akan dibangun dan dikembangkan sistem jaringan yang ada, perangkat yang sering digunakan untuk mengatur bandwidth dan user 
adalah mikrotik, mikrotik merupakan salah satu media yang menyediakan paket lengkap di dalamnya, karena terdapat user management dan bandwidth management di dalamnya. Hal ini dapat memudahkan serta membuat pengguna nyaman dalam menggunakan jaringan yang ada nantinya setelah proses pengembangan.

SMP Negeri 8 Metro merupakan salah satu sekolah menengah pertama yang ada di Kota Metro, sekolah ini terletak di Jalan Kelurahan Karangrejo No.23A, Metro Utara, SMP ini berdiri pada tahun 1998, tujuan didirikannya SMP ini adalah guna memeratakan pendidikan yang ada di Kota Metro, karena SMP ini terletak di perbatasan antara Kota Metro dan Kabupaten Lampung Timur. SMP Negeri 8 Metro memiliki 2 laboratorium yang sampai hari ini masih berfungsi meliputi laboratorium IPA dan Komputer. Jumlah Komputer yang ada di SMP Negeri 8 Metro sebanyak 50 Unit yang terbagi di berbagai ruangan, komputer di laboratorium komputer itu sendiri sebanyak 40 Unit, Ruang Guru 3 Unit dan Perpustakaan 7 Unit Dengan adanya pengembangan jaringan komputer yang ada, hal tersebut dapat membuat fasilitas jaringan komputer dan internet yang ada nantinya menjadi memiliki performa yang optimal, stabil dan dapat meningkatkan konektivitas pada sekolah tersebut, hal tersebut dapat didukung dengan adanya Mikrotik meliputi router atau access point dan perangkat pendukung lainnya. Dengan adanya teknologi router mikrotik yang dapat menghubungkan beberapa komputer dengan memanfaatkan fitur-fitur lain yang ada pada router mikrotik. Oleh karena itu dengan adanya pengembangan sistem, jaringan internet yang ada nantinya dapat mendukung proses belajar mengajar antara guru dan siswa melalui media daring.

\section{KAJIAN LITERATUR Internet}

Putri (2020: 93) menarik kesimpulan bahwa internet merupakan jaringan komputer yang terdiri dari berbagai perangkat komputer yang terhubung melalui protokol untuk memberikan informasi dan internet menyediakan sumber-sumber yang dapat diakses oleh

\section{Internet Service Provider}

Santoso (2012:2) mengambil kesimpulan bahwasanya ISP berasal dari kata internet yang berarti hubungan komputer dengan berbagai tipe yang membentuk jaringan yang mencakup seluruh dunia, service yang berarti pelayanan dan provider yang berarti penyedia jasa internet yakni suatu lembaga atau pengusaha yang menghubungkan komputer pengguna dengan internet. Santoso (2012:2) mengambil kesimpulan bahwasanya Pengertian ISP (Internet Service Provider) adalah perusahaan yang bergerak dalam, jasa pelayanan internet. Perusahaan ini menginvestasikan dananya untuk membangun infrastruktur jaringan internet. Jika kita ingin terhubung ke jaringan internet terlebih dahulu harus menghubungkan komputer kita ke sebuah ISP tertentu dengan mematuhi syarat-syarat yang diberikan ISP tersebut mulai dari besarnya biaya yang dibebankan, kecepatan transfer data, dan juga batas waktu untuk mengakses internet. ISP-ISO di indonesia tergabung dalam asosiasi penyelenggara jasa internet Indonesia.

\section{Jaringan Komputer}

Menurut Wongkar, dkk. (2015:63) jaringan komputer adalah "interkoneksi antara dua komputer Autonomous atau lebih, yang terhubung dengan media transmisi kabel atau tanpa kabel (wireless)". Menurut Wongkar, dkk. (2015:63) Autonomous 
adalah apabila sebuah komputer tidak melakukan kontrol terhadap komputer lain dengan akses penuh, sehingga dapat membuat komputer lain, restart, shutdown, kehilangan file atau kerusakan sistem.

\section{Mikrotik}

Menurut Handriyanto yang dikutip Mustafa, dkk (2019:36) Mikrotik merupakan "sistem operasi Linux base yang diperuntukkan sebagai network router". Menurut Sujarwo, dkk. (2011: 33) yang dimaksud dengan Mikrotik adalah "sebuah perangkat lunak yang termasuk dalam Open Source system namun bukanlah free software, artinya pengguna harus membeli lisensi terhadap segala fasilitas yang disediakan".

\section{Manajemen Bandwidth}

Menurut Santosa yang dikutip Pamungkas (2016:19) Bandwidth merupakan "Kapasitas atau daya tampung kabel Ethernet agar dapat dilewati trafik paket data dalam jumlah tertentu".Bandwidth juga biasa berarti jumlah konsumsi paket data per satuan waktu dinyatakan dengan satuan bit per second (bps). Bandwidth menjadi tolak ukur kecepatan transfer informasi melalui channel. Menurut Santosa yang dikutip Pamungkas (2016:19) Semakin besar bandwidth, semakin banyak informasi yang bisa dikirimkan. Manajemen bandwidth merupakan teknik pengelolaan jaringan sebagai usaha untuk memberikan performa jaringan yang adil dan memuaskan. Manajemen bandwith juga digunakan untuk memastikan bandwidth yang memadai untuk memenuhi kebutuhan trafik data dan informasi serta mencegah persaingan antara aplikasi.

\section{Topologi Jaringan}

Menurut Ginta, dkk (2013:124) yang dimaksud Topologi jaringan komputer atau arsitektur jaringan komputer adalah "pola hubungan antar terminal dalam suatu sistem jaringan komputer yang dapat mempengaruhi tingkat efektivitas kinerja jaringan". Sedangkan menurut Syafrizal yang dikutip oleh Mustafa, dkk (2019:36) yang dimaksud Topologi jaringan adalah "gambaran perencanaan hubungan antar komputer dalam Local Area Network yang umumnya menggunakan kabel (sebagai media transmisi), dengan konektor, Ethernet card, dan perangkat pendukung lainnya"

\section{METODE}

Metode yang digunakan dalam penelitian ini adalah metode Penelitian dan Pengembangan, dalam bahasa inggris disebut Research and Development Method (R\&D). Menurut Sugiyono (2009) R\&D merupakan: "Metode Penelitian dan Pengembangan atau dalam bahasa inggrisnya Research and Development adalah metode penelitian yang digunakan untuk menghasilkan produk tertentu dan menguji keefektifan produk atau sistem tersebut".

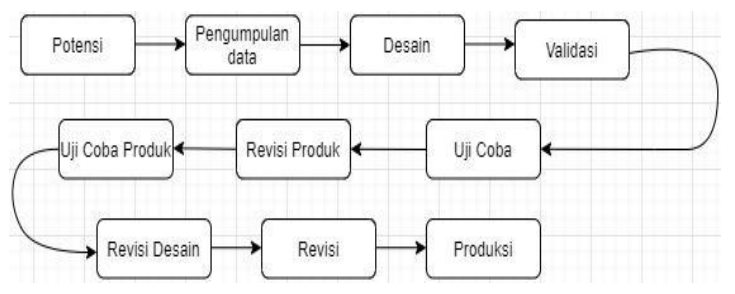

Gambar 1. Diagram R\&D

Teknik pengumpulan data yang digunakan pada penelitian kali ini penulis menggunakan teknik wawancara dan observasi, serta menggunakan metode 4D (define, design, develop, and disseminate) 
Dalam perancangan topologi pada penelitian ini, kali ini penulis menggunakan topologi star sebagai topologi jaringan yang akan dikembangkan di SMP Negeri 8 Metro. Karena topologi ini memiliki kelebihan yang fleksibel, keamanan data yang tinggi dan mudah dalam mendeteksi kerusakan jaringan. Selain itu jika salah satu komputer mengalami kerusakan maka komputer yang lain tidak akan terkena dampaknya. Berikut merupakan topologi yang digunakan pada penelitian ini:

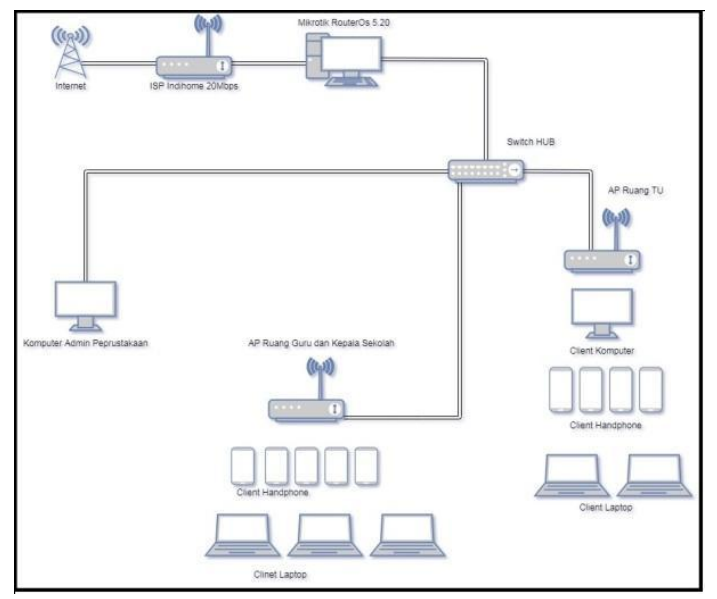

Gambar 2. Topologi Jaringan

\section{Instalasi VirtualBox}

Berikut ini merupakan instalasi virtualbox yang akan digunakan untuk mengkonfigurasi Mikrotik RouterOs.

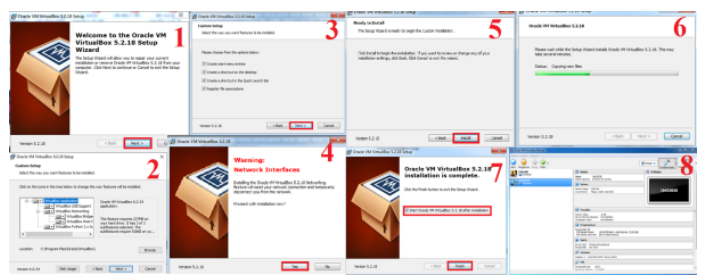

Gambar 3. Instalasi VirtualBox

\section{Instalasi Mikrotik RouterOs}

Berikut ini merupakan instalasi Mikrotik RouterOs yang akan digunakan untuk mengkonfigurasikan jaringan yang ada pada SMP Negeri 8 Metro.
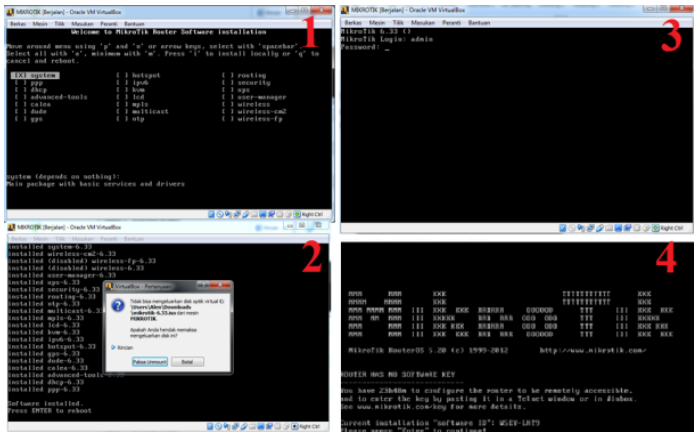

Gambar 4. Instalasi Mikrotik RouterOs

\section{Konfigurasi Bridge Windows XP dan Mikrotik RouterOs}

Langkah yang tak boleh ditinggalkan sebelum melakukan konfigurasi Mikrotik adalah mengkonfigurasi port yang nantinya menghubungkan MikroTik dan VirtualBox, berikut merupakan proses konfigurasi nya:

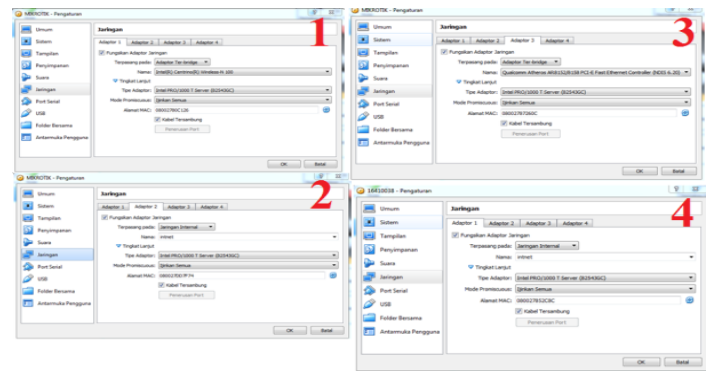

Gambar 5. Konfigurasi Bridge

\section{Konfigurasi Hotspot}

Berikut merupakan konfigurasi hotspot setting menggunakan MikroTik Router.

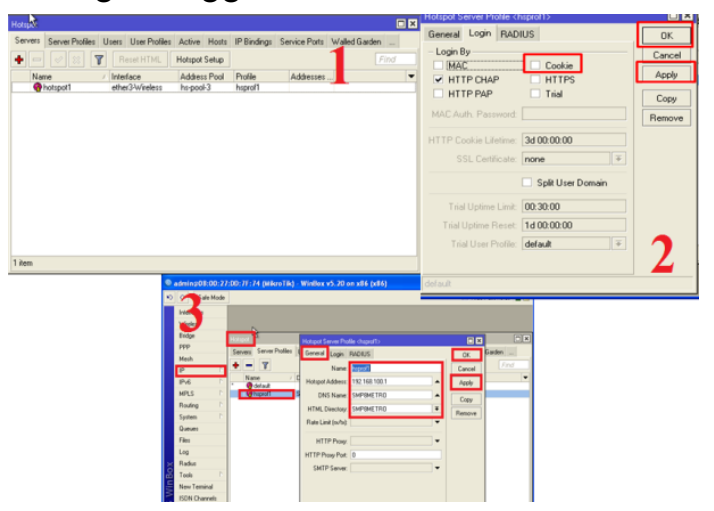

Gambar 6. Konfigurasi Hotspot

\section{Manajemen Bandwith}

Manajemen bandwidth berfungsi untuk mengatur bandwidth dari setiap user yang ada malai dari user jaringan lokal atau 
LAN dan jaringan hotspot agar penggunaan jaringan menjadi lebih baik, cepat, efektif dan efisien.

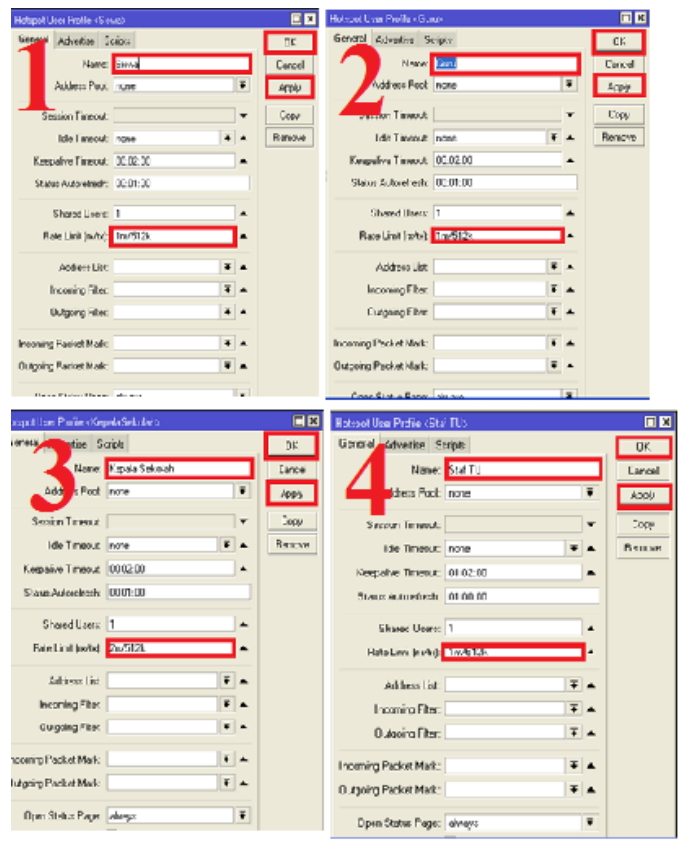

Gambar 7. User Manajemen Bandwith

\section{Testing Jaringan}

Berikut merupakan hasil dari konfigurasi jaringan yang ada pada SMP Negeri 8 Metro, hasil dari konfigurasi berupa manajemen bandwidth yang dapat dilihat pada gambar 8 .

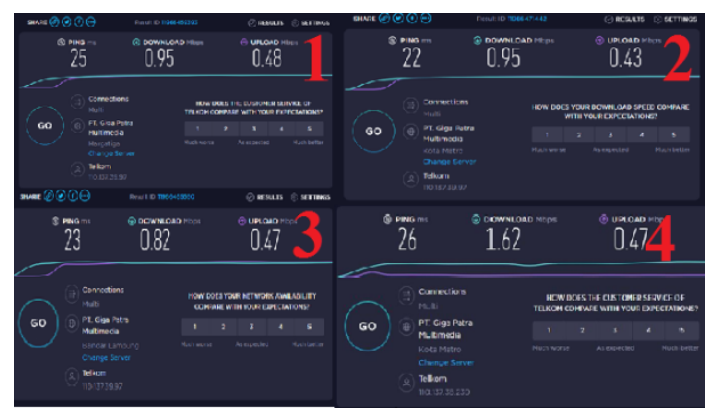

Gambar 8. Testing Jaringan

\section{KESIMPULAN}

Berdasarkan hasil penelitian pengembangan jaringan berbasis MikroTik pada SMP Negeri 8 Metro, tempat penulis melakukan penelitian Skripsi sudah memiliki jaringan internet akan tetapi jaringan yang ada belum memiliki konfigurasi yang baik, jaringan yang ada masih memiliki beberapa masalah antara lain:

a. Jaringan yang ada masih dapat diakses dengan sangat bebas dikarenakan belum adanya konfigurasi username dan password.

b. Jaringan yang ada tidak memiliki manajemen bandwith, sehingga membuat penggunaan jaringan yang ada menjadi tidak efektif dan efisien.

Untuk mengatasi masalah tersebut penulis membuat konfigurasi username dan password yang nantinya antara kepala sekolah guru, siswa dan staf karyawan memiliki akun login hotspot yang berbeda dengan bandwidth yang berbeda juga pada setiap usernya.

Penelitian yang dilakukan kali ini menghasilkan jaringan wireless yang memiliki konfigurasi username dan password serta manajemen bandwith yang memiliki fungsi untuk membuat jaringan yang ada menjadi stabil.

Jaringan yang dibangun kali ini memiliki beberapa kelebihan dibandingkan dengan jaringan yang ada pada sebelumnya, jaringan yang telah dikembangkan memiliki konfigurasi username dan password serta halaman login yang akan otomatis muncul ketika pengguna menyambungkan koneksi ke jaringan internet SMP Negeri 8 Metro. Jaringan yang ada sekarang juga memiliki manajemen bandwidth pada setiap akun penggunanya. Berdasarkan kelebihan tersebut jaringan yang ada sekarang dapat mempermudah kinerja operator jaringan dalam memonitor aktivitas user setelah login ke jaringan internet SMP Negeri 8 Metro.

Untuk menambah referensi pada penelitian selanjutnya ada beberapa saran yang dikemukakan sebagai berikut: 
a. Dikarenakan jaringan internet pada SMP Negeri 8 Metro akan segera ditingkatkan kecepatannya diperlukan pembaharuan konfigurasi, agar setiap user nantinya mendapatkan bandwith yang memiliki kecepatan yang lebih maksimal.

b. Penelitian yang dilakukan oleh penulis menerapkan konfigurasi username dan password, serta manajemen bandwidth yang membuat kinerja jaringan menjadi lebih efektif dan efisien. Penelitian selanjutnya dapat menerapkan Firewall Filtering untuk memaksimalkan penggunaan jaringan yang ada. Serta pada penelitian selanjutnya dapat menerapkan konfigurasi manajemen bandwidth yang lebih akurat lagi menggunakan Metode Queue Tree.

Saran untuk SMP Negeri 8 Metro sebagai tempat penelitian pada penulisan skripsi kali ini antara lain:

a. Jika memang bandwidth yang tersedia masih terasa kurang, perusahaan dapat mengambil langkah untuk mengupgrade ISP bandwidth sesuai dengan yang dibutuhkan.

b. Pihak SMP Negeri 8 Metro harus memiliki satu tenaga ahli untuk mengelola jaringan internet dan komputer pada SMP Negeri 8 Metro.

\section{DAFTAR PUSTAKA}

[1] Asim, Sistematika Penelitian Pengembangan, (Malang: Lembaga Penelitian Universitas Negeri Malang, 2001) hlm. 1.

[2] Ardianto, F., \& Eliza, E. (2016). Penggunaan Mikrotik Router Sebagai Jaringan Server. Jurnal Surya Energy , 1(1), 24-29
[3] Ahmad, L., Munawwir (Ed.). 2018. Sistem Informasi Manajemen. Banda Aceh: Komunitas Informasi Teknologi Aceh (KITA)

[4] Ardianto, F., Akbar, T. 2017. Perancangan Sistem Monitoring Keamanan jaringan Jarak jauh Menggunakan Mikrotik Operating System Melalui Virtual Privat Network, Jurnal Surya Energi 2(1)h. 136

[5] Arafat, F., Sani, A., Ninuk, W., dan Budiyantara, A. 2020. Optimalisasi Jaringan Wireless dengan Metode Wireless System, Jurnal IImiah IImu Komputer,Sains dan Teknologi Terapan 1(2) h. 11-12

[6] Ayudia., Suryanto, E., dan Waluyo, B., 2016. Analisis Penggunaan Bahasa Indonesia Dalam Laporan Hasil Observasi Pada Siswa SMP. Jurnal Penelitian Bahasa, Sastra Indonesia dan Pengajarannya, 4(1), h. 36

[7] Borg W.R. and Gall M.D., Educational Research: An Introduction, 4th edition (London: Longman Inc., 1983).

[8] Firmasyah, A.S., Riadi, I. 2014, Analisis dan Perancangan Proxy Server Menggunakan Virtual Machine, Jurnal Sarjana Teknik Informatika 2(3) h. 3

[9] Ginta, W. G., Kusuma. P, G., dan Negara, K. E. 2013. Implementasi Tools Network Mapper Pada Local Area Network (LAN), Jurnal Media Infotama 9(2) h. 124-127 
[10] Hanafi, 2017. Konsep Penelitian R\&D Dalam Bidang Pendidikan. Jurnal Kajian Keislaman 4(2), h. 133.

[11] Haryati, 2012. Research and Development Sebagai Salah Satu Model Penelitian di Bidang Pendidikan. Majalah IImiah Dinamika 37(1), h.13-14.

[12] Mustafa., Hamzah, A., dan Rachmawati, Y. 2019. Rancangan Infrastruktur Jaringan Backbone Hybrid di Tiga Kampus IST Akprind Yogyakarta, Jurnal Jarkom 6(1) h.36

[13] Muhammad, M. dan Hasan, I. 2016. Analisa dan Pengembangan Jaringan Wireless Berbasis Router Mikrotik OS V.5.20 Di Sekolah Dasar Negeri 24 Palu .Jurnal Elektronik Sistem Informasi dan Komputer, 2(1), h. 11

[14] Pamungkas, A. C. 2016. Management Bandwidth Menggunakan Mikrotik RouterBoard di Politeknik Indonusa Surakarta, Jurnal Informa Politeknik Indonusa Surakarta 1(3) h. 19

[15] Putri, 2020. Pemanfaatan Internet Untuk Meningkatkan Minat Baca Mahasiswa. Jurnal Comm-Edu 3(2) h. 93

[16] Puspitasari, F.N. 2007. Implementasi Mikrotik Sebagai Solusi Router Murah dan Mudah. Makalah disajikan dalam Seminar Nasional Teknologi. Yogyakarta: 24 November 2007
[17] Rustam, 2017. Internet dan Penggunaannya. Jurnal Studi Komunikasi dan Media 21(1), h. 16-17

[18] Riska., Ginta, W.P., Patrick. 2017. Analisa dan Implementasi Wireless Extension Point dengan SSID, Jurnal Media Infotama 13(1) h. 46

[19] Suhadi, Ibnu, Kebijakan Penelitian Perguruan, (Malang: Lembaga Penelitian Universitas Negeri Malang, 2001) hlm. 5.

[20] Solikin, I., dan Amalia, R., 2019. Materi Digital Berbasis WEB Mobile Menggunakan Model 4D. Jurnal Sistem Informasi, 8(3), h. 323

[21] Sugiyono, Metode Penelitian Pendidikan, (Bandung: Alfabeta, 2008) hlm. 409.

[22] Saputra, H. B., \& Basten, A. (2014). Sistem Jaringan Komputer. 1.

[23] Syafrizal, Melwin, 2005, Pengantar Jaringan Komputer, CV. Andi Offset, Yogyakarta.

[24] Sujalwo., Handagar, B., dan Supriyono, H. 2011. Manajemen Jaringan Komputer Dengan Menggunakan Mikrotik Router, Jurnal KomuNiti 2(2) h. 33

[25] Sitanggang, R. 2019. Sistem Informasi Laporan Penjualan Berbasis LAN, Jurnal Mahajana Informasi 4(1) h. 69

[26] Suselo, T. 2011. Subnetting Local Area Network Berbasis Variable. http://e-journal.uajy.ac.id/5555/1/TF76 106.pdf. 1 Janujari 2020 (13.26) 
[27] Santoso., Nurmalina, R. 2017. Perancangan dan Pengembangan Aplikasi Absensi Mahasiswa Menggunakan Smart Card Guna Pengembangan Kampus Cerdas, Jurnal Integrasi 9(1) h.86-87

[28] Wongkar, S., Sinsuw, A., dan Najoan, X. 2015. Analisa Implementasi Jaringan Internet Dengan Menggabungkan Jaringan LAN dan WLAN di Desa Kawangkoan Bawah Wilayah Amurang II, E-Journal Teknik Elektro dan Komputer 4(6) h. 63-64

[29] Yuhana, N. A. dan Aminy, A. F. 2019. Optimalisasi Peran Guru Pendidikan Agama Islam sebagai Konselor dalam Mengatasi Masalah Belajar Siswa. Jurnal Penelitian Pendidikan Islam, 7(1), h. 92 